\title{
Detection of Serum Biomarkers In Hepatocellular Carcinoma Patients
}

Fathia El- Halawany ${ }^{1}$, Seham Mahmoud ${ }^{2}$, Mohamed Radwan Oun ${ }^{3}$, Mohmed Kadry ${ }^{4}$, Hayam Tarek ${ }^{4}$, Rafik Hanna $^{4}$, Mawada Mostafa ${ }^{4}$, Shiran Ayman ${ }^{4}$,Ahmed Abdel Haleem ${ }^{5}$, Ahmed Mohamed ${ }^{4}$, Aya Osama ${ }^{4}$, Bassant Hassan ${ }^{4}$ and Nouran Mohamed ${ }^{4}$

${ }^{1}$ Statistics Department, Faculty of Science for Girls, Jeddah University Jeddah.

${ }^{2}$ Tropical Department, El Sahel Teaching Hospital, Egypt.

${ }^{3}$ Faculty of Pharmacy (Boys)- Al Azahar University.

${ }^{4}$ Biochemsitry and molecular biology department,

Faculty of Biotechnology, Misr Science and Technology.

${ }^{5}$ Tropical Department, National Hepatology and Tropical Medicine Institute.

Cairo, Egypt

\begin{abstract}
Scientific background: HCC has increased significantly in the last decade, as the major risk factors are chronic infections with hepatitis $B$ and $C$ viruses $(H B V \& H C V)$, other risk factors involve aflatoxin B1 exposure, pesticides, alcohol consumption, and genetic defects. New serum tumor markers are required for the diagnosis of HCC instead of alpha-fetoprotein (the most widely used marker) as it's diagnostic accuracy is poor.

Aim: To assess the diagnostic accuracy of serum AFP, AFP-L3, soluble Fas (sFas) and soluble Fas Ligand (sFasL) levels as biomarkers for the diagnosis of HCC. Subjects and Methods: 100 adult patients were selected for this study. Fifty (50) healthy subjects, age and sex-matched, were considered as controls. Routine tests for liver cirrhosis \& HCC were done. Serum sFas and sFasL levels were measured using enzyme-linked immunosorbent assay. Results: Serum AFP, AFPL3, sFas, and sFasL levels were significantly elevated in HCC group when compared with other 2 groups. At a cut off level AFP $\geq 20 \mathrm{pg} / \mathrm{ml}$, the sensitivity and specificity were 70 and 77 respectively. Serum sFas had sensitivity and specificity much better than AFPL3 in the diagnosis of HCC. Regarding serum sFasL level for diagnosis of HCC, it had $87 \%$ sensitivity, $84 \%$ specificity at a cut off level $\geq 17.5 \mathrm{pg} / \mathrm{ml}$. Conclusions: The results of this present study clearly demonstrate that serum sFas and sFasL had a better sensitivity and specificity than AFP in differentiating patients with HCC from those with cirrhosis. $s$ FasL could be used as the best reliable biomarkers in HCC resulting from chronic hepatitis $C$.
\end{abstract}

Keywords: Hepatocellular carcinoma, Liver Cirrhosis, Alfa Feto Protein.

\section{INTRODUCTION}

Hepatocellular carcinoma (HCC) is one of the most common serious cancers worldwide, and a leading cause of death in Africa and Asia (But et al., 2008). In Egypt, the incidence rate of HCC has increased significantly in the last decade, as the major risk factors are chronic infections with hepatitis B and C viruses (HBV \& HCV), other risk factors involves aflatoxin B1 exposure, pesticides, alcohol consumption, and genetic defects (El-Zayadiet al., 2010), although great efforts have been made in the research of therapies for HCC, It is still a malignant disease with poor prognosis, high rate of recurrence, and metastasis (Mazzoccoliet al., 2016). So the most urgent needs are to find sensitive markers for early diagnosis and monitoring of postoperative recurrence of HCC and to give an accurate treatment for HCC patients (Yao et al., 2007). It has been suggested that AFP-L3, appears to be produced only by cancer cells also, as a sensitive and specific marker for HCC (Li et al., 2001). 
Apoptosis is an important mechanism for controlling the balance between cell proliferation and cell death. Related proteins and their receptors on the cells, which associate with the inhibition or augmentation of cell death, help in regulating apoptosis. One of the key receptor-activated apoptotic pathways involves the Fas-Fas ligand system . Furuya et al 2001 and Lim et al 2002 . Fas consist of a homodimer of two identical protein subunits. The membrane isoform (mFas) induces apoptosis in normal or tumor cells, whereas the soluble isoform (sFas) is thought to block Fas-mediated apoptosis by binding and subsequent inactivation of FasL (Marsik et al 2003). FasL has belonged to the tumor necrotic factor (TNF) family. Soluble FasL (sFasL) is generated from its membrane-bound FasL by a metalloproteinase-like protease Tanaka et al 1998. Circulating isoforms of FasL might prevent the recognition of tumor cells by the cytotoxic T-cells by imitating tumor cells as immune-privilege sites Tsutsumi et al 2000. So the aim of this study was to estimate the accuracy of different recent onco biomarkers that can be used and useful for the HCC diagnosis and follow up.

\section{SUBJECT AND METHODS}

This study was a cross-section prospective study. An informed oral and written consent was obtained from all patients. The ethical consideration was informed consent. Sixty patients with liver disease and 20 healthy subjects as control admitted to Hepatology and Gastroenterology Department, Tropical Medicine Hospital. The age of our patients ranges from 30-75 years. These patients were selected for this study according to the following inclusion and exclusion criteria. Exclusion criteria were cases with abnormal renal function. The inclusions criteria were adult patients with liver disease classified as in table 4 . The patients under this study were classified into three groups; twenty healthy subjects (control) group, Group II include 30 patients with liver cirrhosis (LC) and the Group III includes 30 patients with hepatocellular carcinoma (HCC).

All patients will be subjected to the following category ; firstly, thorough history taking with particular attention to manifestations of liver disease especially abdominal ultrasonography and abdominal spiral CT scanning to patients with hepatic focal lesion (table 3) and/or elevated AFP. Secondary full general and local examination of signs of liver disease will be recorded. Finally full investigations of renal function tests (serum creatinine and blood urea) and liver function tests, transaminases (ALT\& AST), serum albumin and prothrombin time (PT) in addition to serum alpha-fetoprotein (AFP). All HCC markers under this study as AFP-L3, Fas and Fas ligand and were detected by Elisa procedures according to manufacturer instructions.

\subsection{Statistical Analysis}

The statistical package (SPSS, version 19.0) was used for data management. Descriptive statistics were presented as mean \pm standard deviations for continuous variables, number, and percentage for categorical variables (frequency distribution).

Unpaired Student t-test (two-sided) was used for detection of the significance between the mean value of studied groups and a chisquare test was used for comparison of categorical variables. The diagnostic value of each marker was assessed using Sensitivity, specificity, positive (PPV) and negative (NPV) predictive values. Receiver operating characteristic curves (ROC) were constructed to assess the validity of the markers in predicting a response by calculating the area under the curve (AUR). The significance level was set at $\mathrm{P}<0.05$.

Table (1): Comparison between the studied groups regarding lab parameters

\begin{tabular}{|c|c|c|c|c|c|}
\hline \multicolumn{2}{|c|}{ Test } & \multirow{2}{*}{$\begin{array}{c}\begin{array}{c}\text { Control group } \\
(\mathbf{N}=\mathbf{5 0})\end{array} \\
57.70 \pm 9.22\end{array}$} & \multirow{2}{*}{$\begin{array}{c}\begin{array}{c}\text { LC group (II) } \\
(\mathbf{N}=\mathbf{5 0})\end{array} \\
60.60 \pm 9.97\end{array}$} & \multirow{2}{*}{$\begin{array}{c}\begin{array}{c}\text { HCC group (III) } \\
(\mathbf{N}=\mathbf{5 0})\end{array} \\
63.15 \pm 12.70\end{array}$} & \multirow{2}{*}{\begin{tabular}{|c|} 
P value \\
0.093
\end{tabular}} \\
\hline Age (years) & Mean & & & & \\
\hline & Range & $33-77$ & $32-78$ & $35-76$ & \\
\hline \multirow[t]{2}{*}{ AIT (U/L) } & Mean & $27.65 \pm 2.69$ & $55.25 \pm 11.38$ & $77.15 \pm 17.7$ & \multirow[t]{2}{*}{0.0001} \\
\hline & Range & $11-31$ & $47-155$ & $55-207$ & \\
\hline \multirow[t]{2}{*}{ AST (U/L) } & Mean & $22.05 \pm 5.31$ & $97.15 \pm 16.33$ & $155.6 \pm 31.27$ & \multirow[t]{2}{*}{0.0001} \\
\hline & Range & $13-34$ & $31-402$ & $80-300$ & \\
\hline Albumin & Mean & $4.01 \pm 1.91$ & $2.53 \pm 0.83$ & $2.79 \pm 0.87$ & 0.0001 \\
\hline
\end{tabular}


International Journal of Advances in Scientific Research and Engineering (ijasre), Vol 5 (1), January-2019

\begin{tabular}{|c|c|c|c|c|c|}
\hline (gram \%) & Range & $2.80-5.10$ & $1.30-3.90$ & $1.70-3.40$ & \\
\hline \multirow{2}{*}{$\begin{array}{l}\text { T. bilirubin } \\
(\mathrm{mg} \%)\end{array}$} & Mean & $0.70 \pm 0.12$ & $5.74 \pm 2.12$ & $3.72 \pm 1.81$ & \multirow[t]{2}{*}{0.003} \\
\hline & Range & $0.40-0.90$ & $1.10-13.40$ & $1.50-6.01$ & \\
\hline \multirow[t]{2}{*}{ P T (sec.) } & Mean & $14.05 \pm 1.23$ & $18.95 \pm 2.17$ & $15.80 \pm 2.91$ & \multirow[t]{2}{*}{0.124} \\
\hline & Range & $13.0-16.0$ & $11.7-16.7$ & $14.2-19.6$ & \\
\hline \multirow{2}{*}{$\begin{array}{c}\text { TLC } \\
\left(\times 10^{3} / \mathrm{cmm}\right)\end{array}$} & Mean & $6.97 \pm 2.10$ & $10.37 \pm 3.98$ & $10.37 \pm 4.31$ & \multirow[t]{2}{*}{0.168} \\
\hline & Range & $4.0-10.2$ & $3.0-16.2$ & $3.0-16.1$ & \\
\hline \multirow[t]{2}{*}{$\mathrm{Hb}(\mathrm{g} / \mathrm{dl})$} & Mean & $13.72 \pm 1.28$ & $10.09 \pm 1.37$ & $11.80 \pm 1.62$ & \multirow[t]{2}{*}{0.0001} \\
\hline & Range & $12.1-15.7$ & $4.1-16.0$ & $9.0-15.0$ & \\
\hline \multirow[t]{2}{*}{ Hct (\%) } & Mean & $42.0 \pm 1.69$ & $28.97 \pm 5.96$ & $28.97 \pm 5.91$ & \multirow[t]{2}{*}{0.0001} \\
\hline & Range & $40-50$ & $13-44.4$ & $13.3-44.4$ & \\
\hline \multirow{2}{*}{$\begin{array}{c}\text { Plt } \\
\left(\times 10^{3} \mathrm{cmm}\right)\end{array}$} & Mean & $255.10 \pm 9.31$ & $167.60 \pm 17.11$ & $107.85 \pm 23.7$ & \multirow[t]{2}{*}{0.0001} \\
\hline & Range & $150-450$ & $48-331$ & $60-160$ & \\
\hline
\end{tabular}

Table 2: Comparison between the studied groups regarding tumor markers

\begin{tabular}{|c|c|c|c|c|c|}
\hline \multicolumn{2}{|c|}{ Test } & $\begin{array}{c}\text { Control group } \\
(\mathbf{N}=\mathbf{5 0})\end{array}$ & $\begin{array}{c}\text { LC group (II) } \\
(\mathbf{N = 5 0})\end{array}$ & $\begin{array}{c}\text { HCC group } \\
(\text { III) (N=50) }\end{array}$ & P value \\
\hline \multirow{2}{*}{ AFP (ng/ml) } & mean & $6.50 \pm 1.20$ & $78.10 \pm 17.20$ & $450.11 \pm 57.20$ & 0.0001 \\
\cline { 2 - 5 } & range & $0.6-8.0$ & $2.7-120.0$ & $12.0-1000.0$ & \\
\hline \multirow{2}{*}{$\begin{array}{c}\text { AFPL3 } \\
(\mathrm{ng} / \mathrm{ml})\end{array}$} & mean & $4.53 \pm 1.81$ & $8.47 \pm 3.01$ & $23.24 \pm 4.29$ & 0.0001 \\
\cline { 2 - 5 } & range & $0.9-7.5$ & $3.0-11.2$ & $3.9-34.6$ & \\
\hline \multirow{2}{*}{ Fas (ng/ml) } & mean & $78.31 \pm 8.25$ & $112.32 \pm 9.11$ & $123.78 \pm 14.97$ & \multirow{2}{*}{0.0001} \\
\cline { 2 - 5 } & range & $67.0-99.0$ & $94.2-123.0$ & $98.1-137.2$ & \\
\hline $\begin{array}{c}\text { Fas Lignad } \\
(\mathrm{ng} / \mathrm{ml})\end{array}$ & mean & $2.59 \pm 1.09$ & $23.68 \pm 8.32$ & $28.54 \pm 10.31$ & 0.0001 \\
\cline { 2 - 5 } & range & $0.8-4.6$ & $7.0-37.0$ & $12.0-46.0$ & \\
\hline
\end{tabular}


International Journal of Advances in Scientific Research and Engineering (ijasre), Vol 5 (1), January-2019

Table 3: Radiological examination of studied groups (Control, LC and HCC patients) Sonar and Computed tomography (CT).

\begin{tabular}{|c|c|c|c|c|}
\hline Parameters & $\begin{array}{l}\text { Control } \\
\mathbf{N}(\%)\end{array}$ & $\begin{array}{c}\text { LC } \\
\text { N (\%) }\end{array}$ & $\begin{array}{c}\mathrm{HCC} \\
\mathrm{N}(\%)\end{array}$ & $P=$ value \\
\hline Liver: & & & & $\mathrm{P}<0.001^{*}$ \\
\hline -Normal Liver & $50(100 \%)$ & $0(0 \%)$ & $0(0 \%)$ & \\
\hline -Bright liver & $0(0 \%)$ & $0(0 \%)$ & $0(0 \%)$ & \\
\hline -Coarse liver & $0(0 \%)$ & $50(100 \%)$ & $50(100 \%)$ & \\
\hline Focal lesion & $0(0 \%)$ & $0(0 \%)$ & $50(100 \%)$ & \\
\hline Ascitis: & & & & $\mathrm{P}=0.008^{*}$ \\
\hline No & $50(100 \%)$ & $30(60 \%)$ & $40(80 \%)$ & \\
\hline Mild & $0(0 \%)$ & $12(23.3 \%)$ & $3(6.7 \%)$ & \\
\hline Mod & $0(0 \%)$ & $5(10 \%)$ & $5(10 \%)$ & \\
\hline Severe & $0(0 \%)$ & $3(6.7 \%)$ & $2(3.3 \%)$ & \\
\hline PVT: & & & & $\mathrm{P}=0.19$ \\
\hline Yes & $0(0 \%)$ & $5(10 \%)$ & $5(10 \%)$ & \\
\hline No & $50(100 \%)$ & $45(90 \%)$ & $45(90 \%)$ & \\
\hline Splenomegaly: & & & & $\mathrm{P}=0.01 *$ \\
\hline Yes & $0(0 \%)$ & $5(10 \%)$ & $40(80 \%)$ & \\
\hline No & $50(100 \%)$ & $45(90 \%)$ & $10(20 \%)$ & \\
\hline Hepatomegaly: & & & & $\mathrm{P}=0.12$ \\
\hline Yes & $0(0 \%)$ & $5(10 \%)$ & $10(20 \%)$ & \\
\hline No & $50(100 \%)$ & $45(90 \%)$ & $40(80 \%)$ & \\
\hline Hypertension: & & & & $\mathrm{P}=0.052$ \\
\hline Yes & $0(0 \%)$ & $5(10 \%)$ & $0(0 \%)$ & \\
\hline No & $50(100 \%)$ & $45(90 \%)$ & $50(100 \%)$ & \\
\hline
\end{tabular}




\begin{tabular}{|c|c|c|c|c|}
\hline $\begin{array}{r}\text { Table 4: Sen } \\
\text { and } F\end{array}$ & $\begin{array}{l}\text { ty and specific } \\
\text { ignad detectio }\end{array}$ & $\begin{array}{l}\text { of diag } \\
\text { HCC }\end{array}$ & $\begin{array}{l}\text { ic values of } \\
\text { ffferent subj }\end{array}$ & $\begin{array}{l}\text { AFPL3, Fas } \\
\text { cases. }\end{array}$ \\
\hline Test & Cut-off value & $\mathbf{A U C}$ & Sensitivity & Specificity \\
\hline AFP & $>20 \mathrm{ng} / \mathrm{ml}$ & 0.67 & $70 \%$ & $77 \%$ \\
\hline AFPL3 & $>29 \mathrm{ng} / \mathrm{ml}$ & 0.76 & $80 \%$ & $80 \%$ \\
\hline Fas & $>147 \mathrm{ng} / \mathrm{ml}$ & 0.83 & $85 \%$ & $82.7 \%$ \\
\hline Fas Lignad & $>17.5 \mathrm{ng} / \mathrm{ml}$ & 0.85 & $87 \%$ & $84 \%$ \\
\hline
\end{tabular}

\section{RESULTS AND DISCUSSION}

This study was conducted on two groups of patients plus a control group without non-significant difference of mean age between subjected cases and control groups (table 1). These classifications were in accordance with the observation of our obtained data in table 4 for all groups. Transaminases, total bilirubin, and prothrombin time observation indicate significant elevation levels in Liver cirrhosis and HCC cases compared with control healthy individuals (table 1). The albumin, platelets, hemoglobin, and hematocrit recorded significant decreasing levels in liver cirrhosis group compared with hepatocellular carcinoma group (table 1).

As regards AFP induce a significant difference between the HCC group and healthy control and liver cirrhosis group, $(\mathrm{P}=0.001)$ as in table 2 .

To compare the three groups with regards to liver texture table 3 illustrated these characteristics also to compare the presence of a focal lesion, ascites, portal vein hypertension, splenomegaly, and hypertension.

Serum AFP, AFPL3, sFas, and sFasL levels were significantly elevated in HCC group in comparison with other 2 groups.

This study showed that AFP has a specificity $77 \%$ and sensitivity $70 \%$ with a cut-off point less than $20 \mathrm{ng} / \mathrm{ml} \mathrm{in} \mathrm{HCC}$ comparing with different subjects while AFPL3 was recorded specificity $80 \%$ and sensitivity $80 \%$ with cut off value $29 \mathrm{ng} / \mathrm{ml}$. Regarding Fas recorded high specificity 82.7 and sensitivity is 85 while for Fas Ligand specificity and sensitivity increase to be 84 and 87 respectively (table 4). So that serum sFas and sFasL had a better sensitivity and specificity than AFP in differentiating patients with HCC from those with cirrhosis. $\mathrm{sFas}$ and $\mathrm{sFasL}$ could be used as reliable biomarkers for HCC resulting from chronic hepatitis $\mathrm{C}$.

\subsection{Discussion}

Total serum AFP more than $200 \mathrm{ng} / \mathrm{ml}$ was highly suggestive for the diagnosis of HCC patients with liver disease with about $100 \%$ predictive for HCC; in addition, AFP-L3 is associated with a seven-fold increased risk of HCC developing (Chrzanowsk $\boldsymbol{e t}$ al., 2008). Based on retrospective observations for patients with total AFP level less than $200 \mathrm{ng} / \mathrm{ml}$, the AFP-L3 biomarker specificity approaches $100 \%$ for HCC when its percentage exceeds $35 \%$ of the total AFP (Leerapunet al., 2007). Chrzanowsk et al., (2008) suggested that this biomarker (AFP \& AFP-L3) increase in HCC and this agreement with Ikemoto et al., (2001) studies. In our study, AFP sensitivity was $70 \%$ and specificity was $77 \%$ at cut-off value more than $20 \mathrm{ng} / \mathrm{ml}$ (table 3 ), while in a previous recent study the best cutoff was $10 \mathrm{ng} / \mathrm{ml}$ with sensitivity $66.3 \%$ and specificity $80.6 \%$ when used as a screening test (Biselli et al., 2015). Usually, patients with a higher AFP level were associated with more severe cirrhosis, more frequent

vascular invasion, higher tumor burden, and poorer performance status. Patients with AFP less than $20 \mathrm{ng} / \mathrm{mL}$ had significantly better long-term survival than patients with AFP more than $20 \mathrm{ng} / \mathrm{mL}$ and patients with AFP less than $400 \mathrm{ng} / \mathrm{mL}$ had significantly better overall outcome than patients with AFP more than $400 \mathrm{ng} / \mathrm{mL}$ (Hsu et al., 2015).

It is important to emphasize that the American Association for the Study of Liver Disease (AASLD) guidelines remove AFP as a primary screening and surveillance modality for HCC due to the lack of sensitivity and specificity. In the present suggestion, AFP-L3 with a cut-off value more than $29 \mathrm{ng} / \mathrm{ml}$ was obtained the sensitivity (80\%) and specificity 80\% (table 3) in agree with Choi et al., (2013) who observed that the AFP-L3 was higher in HCC than in benign liver disease among patients with low AFP levels $(>20 \mathrm{ng} / \mathrm{ml})$ while the sensitivity was $71.1 \%$ and specificity $83.8 \%$ with a cut-off value $5 \%$ in patients with HCC. The AFP- 
L3 fraction has been reported to be more sensitive than AFP for small sized or early stage HCC (Tamura et al., 2010 and Shirakeet al., 1995). In accordance with our obtained data, the AFP-L3 is although known to be highly specific for HCC and reflected tumor characteristics including poor differentiate or malignant invasion (Khian et al., 2001). The majority of the HCC shows one or more alterations in the Fas pathway molecules, which inhibit Fas-mediated apoptosis (Lee et al 2007). The Fas receptor/ligand system including soluble forms is the most important apoptotic initiator in the liver(Pelli et al 2007). Several cells in the liver had been shown to express Fas/FasL and their soluble forms sFas/sFasL that play a major role in the pathogenesis of many liver diseases (Pinkoski et al 2000). In this study, we didn't find any significant difference between HCC patients compared to cirrhosis patients or control patients as regards to age. In HCC patients the age ranged from (35-76) years with mean age of incidence $(63.1 \pm 12.7)$ years old. El Zayadi et al 2001, reported that analysis of age distribution among HCC patients revealed that the most predominant age group was (50-69 years). Also, in the present study, HCC patients were more common in males than females; these results are similar to Zakhary et al 2011 who reported that males represented $70.8 \%$ of all patients in HCC group, with $83.3 \%$ of patients over 50 years.

The present study revealed that the mean values of serum AFPL3, sFas, sFasL and AFP were significantly elevated in HCC group when compared with the other two groups. Nagao et al 1999, Chen et al 2001 and Peng et al 2001 found that the sFas levels in HCC patients were significantly higher than those in controls. Raghuraman et al 2005, found that patients infected with HCV had higher values of sFas compared to healthy and human immunodeficiency virus 1 infected individuals. Hassan et al 2007, showed that the mean value of serum sFas in Bilharzial fibrosis and liver cirrhosis, with and without HCC, was significantly higher than in the control group. El Bassiouny et al 2008, found that sFas was significantly increased in chronic hepatitis C, liver cirrhosis, and HCC cases compared with normal controls. The increase of sFas in HCC was also significantly higher than that of chronic hepatitis C. Zekri et al $\mathbf{2 0 1 0}$ found that HCC patients had also significantly higher levels of sFas when compared to controls. Hammam et al 2012, found the sFas in cirrhotic patients and HCC were significantly higher than that in normal controls and chronic hepatitis $\mathrm{C}$ without cirrhosis, but there was no significant difference between cirrhotic and HCC patients. Lapinski et al 2004, found that sFasL was not detected in healthy subjects, Furthermore, sFasL occurred more frequently in chronic hepatitis $\mathrm{C}$ patients in comparison to chronic hepatitis B patients. Nada et al 2005, found that sFasL levels were higher in HCC than in chronic hepatitis or liver cirrhosis. In our study We found that sFasL levels were significantly elevated in HCC group when compared with the other 2 groups and this was in agreement of Hassan et al 2007 who found that the mean value of serum sFasL was significantly elevated in all patients with liver cirrhosis, with and without HCC, and lower, but not significantly, in patients with Bilharzial fibrosis compared to the control group. On the other hand, Nagao et al 1999 and Chen et al 2005 found that the sFasL levels were significantly lower in patients with HCC when compared to the patients with hepatitis or liver cirrhosis.

\section{CONCLUSION}

Results in this present study clearly demonstrate that serum sFas and sFasL had a better sensitivity and specificity than AFP in differentiating patients with HCC from those with cirrhosis. s FasL could be used as reliable biomarkers for HCC resulting from chronic hepatitis $\mathrm{C}$.

\section{Competing interests}

The authors declare that they have no competing interests.

\section{REFERENCES}

[1] Biselli M, Conti F, Gramenzi1 A, Frigerio M, Cucchetti A, Fatti G, D’Angelo M, Dall'Agata M, Giannini EG, Farinati F, Ciccarese F, Andreone P, Bernardi M, Trevisani F, (2015): A new approach to the use of a-fetoprotein as surveillance test for hepatocellular carcinoma in patients with cirrhosis. British J of Cancer,112, 69-76.

[2] But DYK, Lia, Yuen MF (2008): Natural history of hepatitis-related hepatocellular carcinoma. World Gastro enroll.; 14 (11) $1652-1656$.

[3] Chen J, Su XS, Jiang YF, Gong GZ, Zheng YH, Li GY. Transfection of apoptosis-related gene Fas ligand in human hepatocellular carcinoma cells and its significance in apoptosis. World J Gastroenterol 2005 May; 11(17):2653-2655.

[4] Chen J, Zheng XH, Tang XP. A comparative study of serum sFas in patients with hepatocellular cancer and chronic hepatitis. Hunan Yi Ke Da XueXueBao 2001 Apr; 26(2):173-174.

[5] Choi JY, Jung SW, Kim HY, Kim M, Kim Y, Kim DG, EJ (2013): Diagnostic value of AFP-L3 and PIVKA-II in hepatocellular carcinoma according to total-AFP. World J Gastroenterol. 2013 Jan 21; 19(3): 339-346. 
International Journal of Advances in Scientific Research and Engineering (ijasre), Vol 5 (1), January-2019

[6] Chrzanowska A, Krawczyk M, Baranczyk-Kuzma A (2008): Changes in arginase isoenzymes pattern in human hepatocellular carcinoma. BiochemBiophys Res Commun 377: 337-340.

[7] El Bassiouny AE, El-Bassiouni, Nosseir MM, Zoheiry MM, El-Ahwany EG, Salah F, et al. Circulating and Hepatic Fas Expression in HCV-Induced Chronic Liver Disease and Hepatocellular Carcinoma. Medscape J Med 2008 Jun; $10(6): 130$.

[8] El-Zayadi A, Abaza H, Shawky S, Mohamed MK, Selim OE, Badran HM. Prevalence and epidemiological features of hepatocellular carcinoma in Egypt- single center experience.Hepatol Res 2001; 19(2): 170-179.

[9] El-Zayadi AR, Badran HM, Shawky S, Emara S, El-Bareedy A, Sobhi M. Effect of surveillance for hepatocellular carcinoma on tumor staging and treatment decisions in Egyptian patients. Hepatol Int 2010;4:500-6.

[10] Furuya Y, Fuse H, Masai M. Serum soluble Fas level for detection and staging of prostate cancer. Anticancer Res 2001 SepOct; 21(5):3595-3598.

[11] Hammam O, Mahmoud O, Zahran M, Aly S, Hosny K, Helmy A, et al. The role of Fas/Fas ligand system in the pathogenesis of liver cirrhosis and hepatocellular carcinoma.Hepat Mon 2012 Nov; 12(11):e6132.

[12] Hassan AA, Abuel Fadl A, El-Abd A, Abdel Salam F, Negm M. Usefulness of serum sFas and sFasLdeterminations as apoptogenic markers in liver disease. Biochimica Clinica 2007; 31(2):122-126.

[13] Hsu CY, Li p, Lee YH, Hsia CY, Huang YH, Lin HC, Chiou YY, Lee FY, Huo TL (2015): Using serum $\alpha$-Fetoprotein for prognostic prediction in patients with hepatocellular carcinoma: what I the most optimal cutoff? PLOS One. 10 (3), 1-12.

[13] Lapinski TW, Kowalczuk O, Prokopowicz D, Chyczewski L. Serum concentration of sFas and sFasL in healthy HBsAg carriers, chronic viral hepatitis B and C patients. World J Gastroenterol 2004 Dec; 10(24):3650-3653.

[14] Leerapun A, Suravarapu SV, Bida JP, Clark RJ, Sanders EL, Mettler TA, Stadheim LM, Aderca I, Moser CD, Nagorney DM, LaRusso NF, de GroenPC,Menon KV, Lazaridis KN, Gores GJ, Charlton MR, Roberts RO, Therneau TM, Katzmann JA, Roberts LR (2007): The utility of Lens culinaris agglutinin-reactive alpha-fetoprotein in the diagnosis of hepatocellular carcinoma: evaluation in a United States referral population. ClinGastroenterolHepatol. 2007 Mar; 5(3):394-402.

[15] Li D, Mallory T, Satamura S (2001): AFP-L3 a new generation of tumor marker for hepatocellular carcinoma. Clinica.Chemica.Acta; 31:15-19.

[16] Lim SC. Expression of Fas ligand and sFas ligand in human gastric adenocarcinomas.Oncol Rep 2002 Jan-Feb; 9(1): 103107.

[17] Khien VV, Mao HV, Chinh TT, Ha PT, Bang MH, Lac BV, Hop TV, Tuan NA, Don LV, Taketa K, Satomura S (2001): Clinical evaluation of lentil lectin-reactive alpha-fetoprotein-L3 in histology-proven hepatocellular carcinoma. Int $\mathrm{J}$ Biol Markers. 2001 Apr-Jun; 16 (2):105-111.

[18] Marsik C, Halama T, Cardona F, Wlassits W, Mayr F, Pleiner J, et al. Regulation of Fas (APO- 1, CD95) and Fas ligand expression in leukocytes during systemic inflammation in humans. Shock 2003 Dec; 20(6): 493-496.

[19] Mazzoccoli G, R. Tarquini, A. Valoriani, J. Oben, M. Vinciguerra, and F. Marra, "Management strategies for hepatocellular carcinoma: old certainties and new realities," Clinical and Experimental Medicine, vol. 16, no. 3, pp. 243-256, 2016.

[20] Nada O, Abdel-Hamid M, Ismail A, El Shabrawy L, Sidhom KF, El Badawy NM, et al. The role of the tumor necrosis factor (TNF)--Fas L and HCV in the development of hepatocellular carcinoma. J Clin Virol 2005 Oct; 34(2):140-146.

[21] Nagao M, Nakajima Y, Hisanaga M, Kayagaki N, Kanehiro H, Aomatsu Y, et al. The alteration of Fas receptor and ligand system in hepatocellular carcinomas: how do hepatoma cells escape from the host immune surveillance in vivo? Hepatology 1999 Aug; 30(2):413-421.

[22] Pelli N, Floreani A, Torre F, Delfino A, Baragiotta A, Contini P, et al. Soluble apoptosis molecules in primary biliary cirrhosis: analysis and commitment of the Fas and tumor necrosis factor related apoptosis-inducing ligand systems in comparison with chronic hepatitis C. ClinExpImmunol 2007 Apr; 148(1):85-89.

[23] Peng Z, Tang H, Ling Y, Han G. Apoptosis and Fas system are significantly involved in the process of liver cirrhosis converting into hepatocellular carcinoma. J Tongji Med Univ 2001; 21(2):126-9,148. 
International Journal of Advances in Scientific Research and Engineering (ijasre), Vol 5 (1), January-2019

[24] Pinkoski MJ, Brunner T, Green D, Lin T. Fas and Fas ligand in gut and liver. Am J PhysiolGastrointest Liver Physiol 2000 Mar; 278(3): G354-366.

[25] Raghuraman S, Abraham P, Daniel HD, Ramakrishna BS, Sridharan G. Characterization of soluble FAS, FAS ligand and tumor necrosis factor-alpha in patients with chronic HCV infection. J Clin Virol 2005 Sep; 34(1):63-70.

[26] Shiraki K, Takase K, Tameda Y, Hamada M, Kosaka Y, Nakano T (1995): A clinical study of lectin-reactive alphafetoprotein as an early indicator of hepatocellular carcinoma in the follow-up of cirrhotic patients. Hepatology, 1995; 22 (3):802807.

[27] Tamura Y, Igarashi M, Kawai H, Suda T, Satomura S, Aoyagi Y (2010): Clinical advantage of a highly sensitive on-chip immunoassay for a fucosylated fraction of alpha-fetoprotein in patients with hepatocellular carcinoma. Dig Dis Sci. 55(12):35763583.

[28] Tanaka M, Itai T, Adachi M, Nagata S. Downregulation of Fas ligand by shedding. Nat Med 1998 Jan; 4(1): 31-36.

[29] Tsutsumi S, Kuwano H, Shimura T, Morinaga N, Mochiki E, Asao T. Circulating soluble Fas ligand in patients with gastric carcinoma. Cancer 2000 Dec; 89(12): 2560-2564

[30] Yao DF, Dong ZZ, Yao M (2007): Specific molecular markers in hepatocellular carcinoma. HepatobiliaryPancreat Dis Int. Jun; 6(3):241-247.

[31] Lee SH, Shin MS, Lee HS, Bae JH, Lee HK, Kim HS, et al. Expression of Fas and Fas-related molecules in human hepatocellular carcinoma. Hum Pathol 2001 Mar; 32(3): 250-256.

[32] Zakhary NI, El-Merzabani MM, El-Sawi NM, Saleh SM, Moneer MM, Mohamad RH. Impact of different biochemical markers in serum of patients with benign and malignant liver diseases. Journal of Advanced Research 2011; 2(1):49-55.

[33] Zekri AN, Alam El-Din HM, Bahnassy AA, Zayed NA, Mohamed WS, El-Masry SH, et al. Serum levels of soluble Fas, soluble tumor necrosis factor-receptor II, interleukin-2 receptor and interleukin-8 as early predictors of hepatocellular carcinoma in Egyptian patients with hepatitis C virus genotype-4. Comparative Hepatology 2010, 9:1-12. 